\title{
钯催化的乙烯基氨基甲酸酯与烯酮的不对称[8+2]偶极环加成反应
}

\author{
李美琪张勇健*
}

(上海交通大学化学与化工学院 教育部变革性分子前沿科学中心 上海 200240)

\section{Palladium-Catalyzed Asymmetric [8+2] Dipolar Cycloadditions of Vinyl Carbamates and Ketenes}

\author{
Li, Meiqi Zhang, Yongjian* \\ (Frontiers Science Center for Transformative Molecules, School of Chemistry and Chemical Engineering, \\ Shanghai Jiao Tong University, Shanghai 200240)
}

中环骨架广泛存在于许多天然产物与药物分子中. 自从 1960 年 Doering 与 Wiley ${ }^{[1]}{ }^{1}$ 报道了利用 $[8+2]$ 高阶 环加成反应捕获庚富烯的工作后, 这一领域引起了化学 家们的广泛关注. 近年来, 许多 $[8+2]$ 环加成反应被报 道. 但为了降低反应的复杂性和熵垒, 目前这些反应通 常限制于构型固定的共轭 $8 \pi$ 组分, 并且, 大多只能得到 包含十元环的并环化合物 ${ }^{[2]}$. 良好的化学选择性以及对 映选择性控制仍是该领域的一个巨大挑战.

2013 年, 冯小明课题组 ${ }^{[3]}$ 通过路易斯酸催化氮杂庚 富烯与亚烷基丙二酸酯的不对称 $[8+2]$ 环加成反应, 高 效、高立体选择性地构建了具有环庚三烯结构单元的吡 咯衍生物. 2017 年, Jørgensen 小组 ${ }^{[4]}$ 利用有机催化的方 法实现了缺电子的庚富烯与环烯酮的不对称 $[8+2]$ 环加 成反应. 尽管这一领域已经取得了重要的进展, 但是, 通过发展新的概念、新的催化体系, 高效、高立体选择
性地构建十元单环骨架仍然是十分重要的.

近年来，基于钯催化烯丙基烷基化的偶极环加成反 应已经成为构建碳环与杂环化合物的有力工具 ${ }^{[5]}$. 在这 一领域, 乙烯基氨基甲酸酯通过与零价钯的氧化加成, 随后释放二氧化碳，被广泛用作钯稳定偶极体的前体 ${ }^{[6]}$. 基于对过渡金属催化的偶极环加成反应的认识，肖文 精、陆良秋课题组和蓝宇课题组考虑是否可以通过实现 二氧化碳基团的保留, 进而为高阶偶极环加成反应提供 可能.

近日, 该研究团队 ${ }^{[7]}$ 结合钯催化与光活化, 发展了 原位产生的 1,8-偶极子与烯酮之间的不对称偶极环加成 反应, 实现了十元单环产物的高效、高对映选择性构建 (Scheme 1). 研究发现, 乙烯基氨基甲酸酯氮原子上的 保护基对反应有重要的影响. 当使用对甲苯磺酰基( $\mathrm{Ts})$ 作为取代基时，只能产生六元环与八元环混合产物; 而<smiles>C=CC1(c2ccccc2)CCN([As])C(=O)O1</smiles>
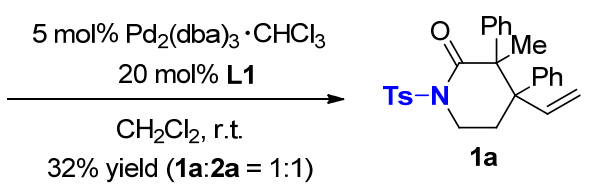<smiles>[2H]C1(C)CC=C(c2ccccc2)CCN([As])C1=O</smiles>

2a<smiles>C=CC1(c2ccccc2)CCN(C(C)(C)C)C(=O)O1</smiles>

$\mathrm{PMB}=4-\mathrm{OMe}-\mathrm{C}_{6} \mathrm{H}_{4} \mathrm{CH}_{2}$

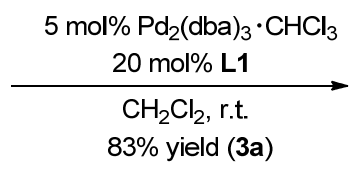

$83 \%$ yield (3a)

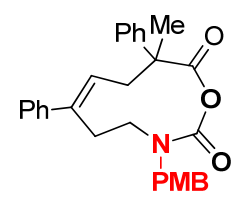

3a<smiles>CN(C)p1oc2ccc3ccccc3c2c2c(ccc3ccccc32)o1</smiles>

L1

图式 1 氮原子的保护基对 $[8+2]$ 偶极环加成反应的影响

Scheme 1 Effect of nitrogen atom protection on [8+2] dipolar cycloadditions

* Corresponding author. E-mail: yjian@sjtu.edu.cn. Published online September 3, 2020. 
当使用对甲氧基苄基(PMB)作为取代基时，在相同条件 下可以得到目标十元环化合物. 随后, 研究人员进一步 从不对称催化的角度对该反应进行了探究. 通过一系列 研究发现, 使用该课题组自主研发的手性 P,S 配体时, 该反应可以实现 99\%的产率以及 $96: 4$ 的对映体比例. 最终, 他们得出结论, 手性联䒺酚(BINOL)与手性二苯 乙基两种手性骨架的匹配是实现高对映选择性的关键. 随后，在 6W LED 蓝光灯照射下，使用 $\alpha$-重氮酮替代烯 酮，在相同反应条件下可以以 $49 \%$ 的核磁收率以及 $96: 4$ 的对映体比例得到目标产物(Scheme 2). 通过进 一步调整反应操作, 可以以 $99 \%$ 的核磁收率得到产物, 同时对映选择性得到保持.

该方法的底物适用性广、官能团兼容性强, 对于不 同的底物都可以实现较高的产率及对映体选择性. 同 时, 克级反应可以以 $81 \%$ 的产率及 $96: 4$ 的对映体比例 得到产物. 此外, 在 $180{ }^{\circ} \mathrm{C}$ 与无溶剂的条件下, 使用微 量的 $N$-甲基哌啶处理产物, 可以将十元环产物转换为 八元环产物, 产率适中, 并且实现了光学纯度的保持 $\left(\right.$ Scheme 3) ${ }^{[8]}$.

蓝宇等 ${ }^{[7]}$ 的密度泛函理论计算表明, 钯对于底物乙 烯基氨基甲酸酯的氧化加成过程是反应的决速步骤. 同 时，通过分析反应的活化能差异发现，当使用对甲氧基 苄基作为取代基时，底物通过释放二氧化碳产生两性离 子中间体的过程相比于直接对烯酮的亲核加成过程更 困难. 当使用对甲基磺酰基作为取代基时，却得到了相 反的趋势, 对键级与键长的进一步比较也印证了这一结 论. 当使用对甲氧基苄基作为取代基时，通过破坏碳一 氮键来释放二氧化碳变得更加困难. 在分子内环化一 步，通过线性选择性的烯丙基取代产生十元环产物相比 于通过支链选择性过程产生八元环产物，具有更低的活 化能，因此更容易形成. 这些计算结果与实验观察一致. 陆良秋团队首次报道了钯催化的乙烯基氨基甲酸酯与 光催化生成的烯酮的不对称 [8+2]高阶偶极环加成反 应. 该研究为构建含有手性季碳中心的十元化合物提供 了一种条件温和、立体选择性高的新方法，同时也为构 建中型单环体系提供了新的思路.

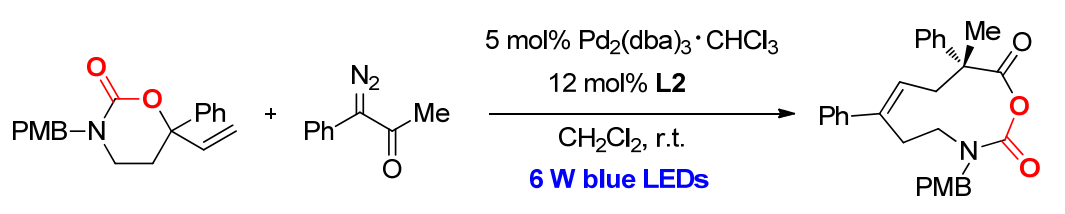

All-in procedure: 49\% yield; stepwise, one-pot procedure: $99 \%$ yield; $96: 4$ er

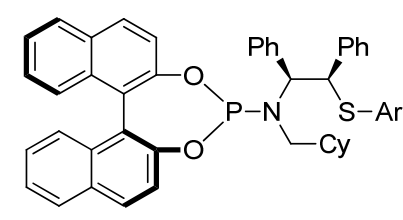

L2: $\mathrm{Ar}=4-\mathrm{Br}-\mathrm{C}_{6} \mathrm{H}_{4}$

图式 2 钯催化的不对称的 $[8+2]$ 偶极环加成反应

Scheme 2 Palladium-catalyzed asymmetric [8+2] dipolar cycloadditions

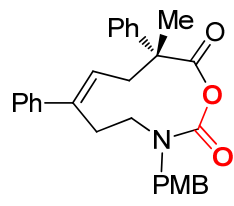

3a $(96: 4$ er $)$

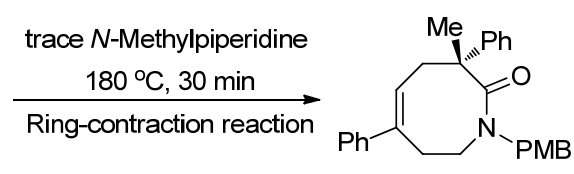

4a $(41 \%, 96: 4$ er $)$

图式 3 产物的转化

Scheme 3 Product transformation

\section{References}

[1] von E. Doering, W.; Wiley, D. W. Tetrahedron 1960, 11, 183.

[2] Chen, Y. Y.; Ye, S. Y.; Jiao, L.; Liang, Y.; Sinha-Mahapatra, D. K.; Herndon, J. W.; Yu, Z. X. J. Am. Chem. Soc. 2007, 129, 10773.

[3] Xie, M. S.; Liu, X. H.; Wu, X. X.; Cai, Y. F.; Lin, L. L.; Feng, X. M. Angew. Chem., Int. Ed. 2013, 52, 5604

[4] Mose, R.; Preegel, G.; Larsen, J.; Jakobsen, S.; Iversen, E. H.;
Jørgensen, K. A. Nat. Chem. 2017, 9, 487.

[5] Butt, N. A.; Zhang, W. B. Chem. Soc. Rev. 2015, 44, 7929.

[6] Leth, L. A.; Glaus, F.; Meazza, M.; Fu, L.; Thøgersen, M. K.; Bitsch, E. A.; Jørgensen, K. A. Angew. Chem., Int. Ed. 2016, 55, 15272 .

[7] Zhang, Q. L.; Xiong, Q.; Li, M. M.; Xiong, W.; Shi. B.; Lan, Y.; Lu, L. Q.; Xiao, W. J. Angew. Chem., Int. Ed. 2020, 59, 14096.

[8] Dean, C. S.; Tarbell, D. S. J. Org. Chem. 1971, 36, 1180.

(Zhao, C.) 